\title{
Pengaruh Berat Beban pada Lengan terhadap Gaya Otot Bisep Sebagai Media Pembelajaran IPA Konsep Bioekanika
}

\author{
Hanif Alifah Kurniawati, Heru Kuswanto, Febyarni Kimianti, Wahyu \\ Pamungkas \\ Prodi Pendidikan Sains, Program Pascasarjana, Universitas Negeri Yogyakarta \\ hanifalifahk.2017@student.uny.ac.id
}

\begin{abstract}
Humans do many activities that use the biomechanical concept. Biomechanics is the science that explains the mechanical aspects of human body movements. Science that uses the laws of physics and mechanics to describe movements in the body and understand the effects of force and moments that occur. The movement of the human body using the biomechanical principle is one of the activities in the arm where there is a bicep muscle when someone lifts an object or load. This study aims to determine the effect of the weight on the arm on the force of the biceps in a person when lifting an object with mass. This research is an experimental study. Measurement of biceps muscle force using a hand frame tool made of wood by providing load variations namely $0,2 \mathrm{~N} ; 0,4 \mathrm{~N} ; 0,6 \mathrm{~N} ; 0,8 \mathrm{~N}$ and 1,0 $\mathrm{N}$. Every load given in the arm, it will be known the biceps muscle force are measured using a spring balance. The data from research results are analyzed simply and included in the graph. Based on the results of the analysis, it is known that the greater the weight are given to the arm, the greater the force of the biceps.
\end{abstract}

Keywords: biomechanics, biceps muscle force, media of learning

\section{ABSTRAK}

Manusia melakukan banyak kegiatan yang menggunakan konsep biomekanika. Biomekanika adalah ilmu yang menjelaskan tentang aspek mekanika dari gerakan tubuh manusia. Ilmu yang menggunakan hukum fisika dan mekanika untuk mendeskripsikan gerakan pada tubuh dan memahami efek gaya dan momen yang terjadi. Gerak tubuh manusia yang memakai prinsip biomekanika salah satunya adalah kegiatan pada lengan di mana terdapat gaya otot bisep ketika seseorang mengangkat benda atau beban. Penelitian ini bertujuan untuk mengetahui pengaruh berat beban pada lengan terhadap gaya otot bisep pada seseorang ketika mengangkat sebuah benda bermassa. Penelitian ini termasuk penelitian eksperimen Pengukuran gaya otot bisep menggunakan sebuah alat kerangka tangan yang dibuat dari kayu dengan memberikan variasi beban yaitu $0,2 \mathrm{~N} ; 0,4 \mathrm{~N} ; 0,6 \mathrm{~N} ; 0,8 \mathrm{~N}$ and 1,0 N. Setiap beban yang diberikan di lengan, maka akan diketahui gaya otot bisep yang terukur dengan menggunakan neraca pegas. Data hasil penelitian dianalisis secara sederhana dan dimasukkan ke dalam grafik. Berdasarkan hasil analisis diketahui bahwa semakin besar berat beban yang diberikan pada lengan maka gaya otot bisep juga akan semakin besar.

Kata Kunci: biomekanika, gaya otot bisep, media pembelajaran

\section{PENDAHULUAN}

IPA dipahami sebagai ilmu yang berkembang dari proses observasi, perumusan masalah, penyusunnan hipotesis, eksperimen, penarikan kesimpulan, serta penemuan teori dan konsep. Pembelajaran IPA bagi peserta didik pada jenjang SMP idealnya dilakukan secara terpadu. Pembelajaran IPA secara terpadu memiliki beberapa tujuan. BSNP menjabarkan tujuan pembelajaran IPA secara terpadu adalah: meningkatkan efisiensi dan efektivitas, meningkatkan minat dan motivasi, tercapainya beberapa kompetensi dasar sekaligus, 
meningktkan pemahaman konsep yang dipelajari secara lebih bermakna, mengembangkan keterampilan menemukan, mengolah, dan memanfaatkan informasi, menumbuhkembangkan sikap positif, juga menumbuhkembangkan keterampilan sosial ${ }^{[1]}$.

Gerak anggota tubuh merupakan salah satu tema yang di dalamnya terdapat keterkaitan antara konsep fisika dan biologi. Taylor et al. menjelaskan bahwa biomekanika adalah ilmu yang menjelaskan tentang aspek mekanika dari gerakan tubuh manusia. Ilmu yang menggunakan hukum fisika dan mekanika untuk mendeskripsikan gerakan pada tubuh dan memahami efek gaya dan momen yang terjadi. Aktivitas yang dilakukan manusia dalam kehidupan sehari-hari tidak lepas dari gerakan-gerakan yang disebabkan oleh kerja tubuh itu sendiri. Gerak dalam ilmu fisika merupakan perubahan tempat atau kedudukan baik hanya sekali maupun berkali-kali ${ }^{[2]}$.

Tubuh manusia dirancang agar dapat melakukan aktivitas. Bentuk aktivitas yang dilakukan salah satunya adalah berolahraga. Arandi dan Rahayu menjelaskan bahwa olahraga ialah salah satu bagian dari usaha untuk peningkatan diri manusia yang mengarah kepada pembentukan kepribadian, dan lain-lain, dimana dengan melakukan olahraga, manusia dapat dikatakan melakukan salah satu cara untuk menjaga kesehatan serta kebugaran kondisi fisik, karena dengan melakukan olahraga otot-otot yang terdapat pada tubuh manusia yang awalnya pasif akan berubah menjadi aktif untuk berkontraksi, membakar energi sehingga menghasilkan keringat yang berarti kinerja organ pada tubuh manusia bekerja dan berfungsi secara normal ${ }^{[3]}$.

Ketika seseorang melakukan aktivitas atau olahraga, tubuh akan memperoleh beban dari luar tubuhnya. Hal ini berarti setiap aktivitas yang dilakukan adalah beban bagi manusia. Salah satu aktivitas yang mendasar pada manusia yang dijadikan sebagai salah satu kegiatan olahraga adalah gerakan tangan. Gerakan ini ialah gerakan yang terjadi akibat gerakan gabungan antara sendi yang berkaitan dengan sendi-sendi lainya seperti siku dan bahu ${ }^{[4]}$. Ketika tangan seseorang diberikan beban, maka terdapat gaya yang bekerja pada otot bisep. Tujuan dari penelitian ini adalah untuk mengetahui pengaruh berat beban yang diberikan pada lengan terhadap gaya yang bekerja pada otot bisep ketika seseorang melakukan aktivitas fisik mengangkat beban.

\section{METODE}

Penelitian ini merupakan bentuk penelitian eksperimen. Alat dan bahan yang diperlukan dalam pembuatan kerangka lengan yaitu kayu, neraca pegas baut dan mur, meteran, cat kayu, dan alat tulis. Adapun langkah pembuatannya, pertama yaitu menyiapkan alat dan bahan yang diperlukan, kemudian memotong kayu sesuai ukuran yang telah dirancang sebelumnya, dapat dilihat pada Gambar 1, selanjutnya merangkai seperti pada Gambar 2.

Langkah pengambilan data yaitu pertama menyiapkan kerangka lengan yang telah dibuat dan variasi berat beban yang akan diujicobakan. Adapun berat beban adalah 0,2 N; 0,4 N; $0,6 \mathrm{~N} ; 0,8 \mathrm{~N}$ and 1,0 N. Kemudian memberikan beban pada kerangka lengan di bagian ujung (analogi membawa beban dengan jari-jari) dan mengamati gaya yang terukur pada kedua neraca sebagai gaya otot bisep dan gaya siku. Setiap satu jenis beban pengukuran dilakukan hingga lima kali pengulangan untuk mendapatkan gaya rata-rata yang dihasilkan pada gaya otot bisep dan gaya siku pada kerangka lengan yang telah dibuat. Data hasil pengamatan selanjutnya dimasukkan dalam tabel hasil pengamatan. Hasil pengamatan dianalisis secara sederhana. Hasil analisis dituangkan dalam grafik untuk mengetahui pengaruh berat beban yang diberikan pada lengan terhadap gaya otot bisep dan gaya siku yang dihasilkan.

Neraca pegas yang dipasang pada kerangka lengan berjumalh dua buah. Satu neraca dipasang di bagian lengan untuk mengetahui seberapa besar gaya otot bisep yang terukur. 
Sedangkan satu neraca dipasang di bagian ujung siku kerangka lengan untuk mengetahui gaya siku yang terukur. Gaya siku ini lebih lanjut digunakan untuk mengetahui momen gaya. Penelitian ini terbatas pada mengetahui pengaruh berat beban terhadap gaya otot bisep yang diperlukan atau dihasilkan ketika seseorang mengangkat beban.

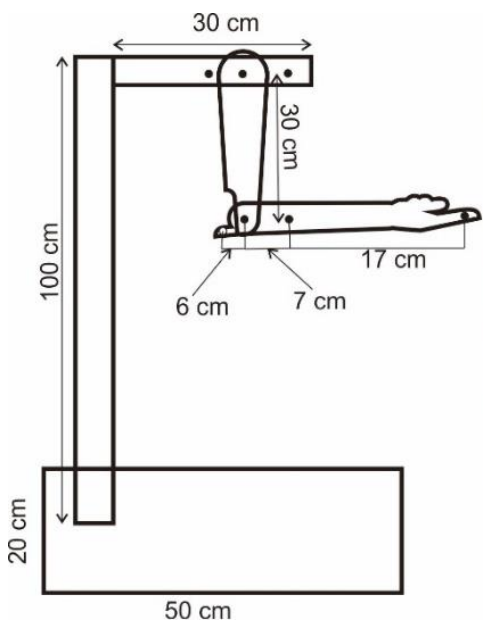

Gambar 1. Ukuran Rancangan Kerangka Lengan

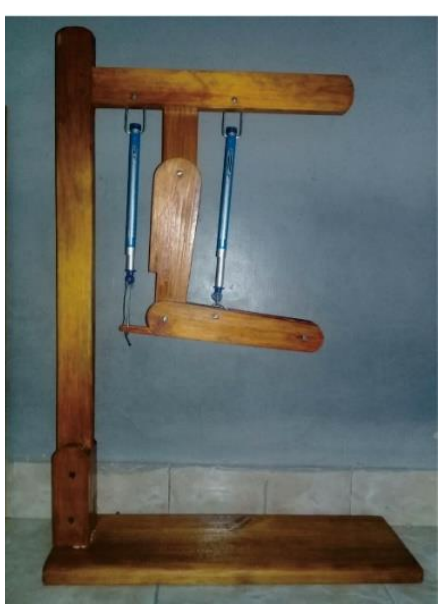

Gambar 2. Kerangka Lengan Siap Digunakan

\section{HASIL DAN PEMBAHASAN}

Ketika tangan seseorang diberi beban maka beban tersebut akan mempengaruhi gaya otot dan momen gaya pada siku. Hal tersebut merupakan salah satu bentuk dari aplikasi konsep biomekanika. Variabel yang dimanipulasi adalah berat beban yaitu $0,2 \mathrm{~N} ; 0,4 \mathrm{~N} ; 0,6 \mathrm{~N} ; 0,8$ $\mathrm{N}$ and 1,0 N. Hasil pengukuran dan pengamatan variasi beban terhadap gaya yang terukur disajikan dalam Tabel 1 dan Tabel 2.

Tabel 1. Gaya yang terukur pada neraca pegas 1 (gaya otot bisep)

\begin{tabular}{ccccccc}
\hline \multirow{2}{*}{$\begin{array}{c}\text { Gaya Otot Bisep (N) } \\
\text { Pada pengukuran ke- }\end{array}$} & \multicolumn{7}{c}{ Berat Beban (N) } \\
\cline { 2 - 7 } & $\mathbf{0}$ & $\mathbf{0 , 2}$ & $\mathbf{0 , 4}$ & $\mathbf{0 , 6}$ & $\mathbf{0 , 8}$ & $\mathbf{1 , 0}$ \\
\hline 1 & 3,6 & 3,8 & 4,3 & 4,6 & 4,9 & 5,3 \\
2 & 3,4 & 3,9 & 4,3 & 4,6 & 4,8 & 5,4 \\
3 & 3,5 & 3,9 & 4,4 & 4,7 & 4,9 & 5,3 \\
4 & 3,4 & 4,0 & 4,4 & 4,7 & 4,9 & 5,4 \\
5 & 3,3 & 3,8 & 4,3 & 4,7 & 4,9 & 5,4 \\
Jumlah & 17,2 & 19,4 & 21,7 & 43,3 & 24,4 & 26,8 \\
Rata-rata & 3,44 & 3,88 & 4,34 & 4,66 & 4,88 & 5,36 \\
\hline
\end{tabular}


Tabel 2. Gaya yang terukur pada neraca pegas 2 (gaya pada siku)

\begin{tabular}{cccccccc}
\hline \multirow{2}{*}{ Gaya Otot Bisep (N) } & \multicolumn{7}{c}{ Berat Beban $(\mathbf{N})$} \\
\cline { 2 - 7 } & $\mathbf{0}$ & $\mathbf{0 , 2}$ & $\mathbf{0 , 4}$ & $\mathbf{0 , 6}$ & $\mathbf{0 , 8}$ & $\mathbf{1 , 0}$ \\
\hline 1 & 2,0 & 1,8 & 1,4 & 1,1 & 0,9 & 0,6 \\
2 & 2,1 & 1,8 & 1,4 & 1,1 & 1,0 & 0,6 \\
3 & 2,1 & 1,8 & $1 ., 3$ & 1,1 & 0,9 & 0,6 \\
4 & 2,1 & $1 ., 7$ & $1 ., 3$ & 1,1 & 0,9 & 0,6 \\
5 & $2 ., 2$ & 1,8 & 1,4 & 1,1 & 0,9 & 0,6 \\
Jumlah & 10,5 & 8,9 & 6,8 & 5,5 & 4,6 & 3,0 \\
Rata-rata & 2,1 & 1,78 & 1,36 & 1,1 & 0,92 & 0,6 \\
\hline
\end{tabular}

Data hasil dari Tabel 1 dan Tabel 2 kemudian dianalisis lebih lanjut. Besar gaya awal pada kerangka lengan sebelum diberi beban bukanlah $0 \mathrm{~N}$, sehingga gaya rata-rata tiap beban dikurangi dengan gaya rata-rata sebelum kerangka lengan sebelum diberi beban. Hasil perhitungan ini yang nantinya digunakan dalam analisis pengaruh berat beban terhadap gaya otot bisep. Hasil perhitungan dapat dilihat pada Tabel 3.

Tabel 3. Hasil Perhitungan Gaya yang Terukur

\begin{tabular}{cccc}
\hline No & Berat beban $(\boldsymbol{N})$ & Gaya Otot Bisep $(\boldsymbol{N})$ & Gaya Siku $(\boldsymbol{N})$ \\
\hline 1 & 0,2 & $0 ., 4$ & 0,3 \\
2 & 0,4 & 0,9 & 0,7 \\
3 & 0,6 & 1,2 & 1 \\
4 & 0,8 & 1,4 & 1,2 \\
5 & 1,0 & 1,9 & 1,5 \\
\hline
\end{tabular}

Data hasil perhitungan pada Tabel 3 selanjutnya dimasukkan dalam grafik. Grafik dibuat untuk mempermudah dalam mengetahui pengaruh berat beban terhadap gaya otot bisep dan momen gaya pada siku ketika seseorang mengangkat benda. Diketahui bahwa momen gaya adalah sebanding dengan gayanya, sehingga apabila gaya semakin besar momen gayanya juga akan semakin besar, begitu pula sebaliknya. Grafik pengaruh berat beban dapat dilihat pada Gambar 1. 


\section{Grafik Pengaruh Beban terhadap Gaya Otot dan Gaya Siku}

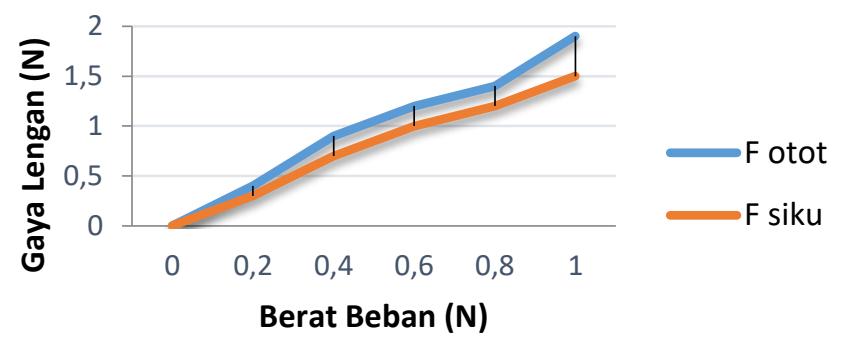

Gambar 1. Pengaruh Berat Beban terhadap Gaya Otot Bisep dan Gaya pada Siku

Berdasarkan hasil perhitungan pada Tabel 3 dan Gambar 1 tampak bahwa semakin besar beban yang diberikan pada kerangka lengan maka semakin besar pula gaya otot bisep dan momen gaya pada siku. Pada berat beban terkecil yaitu $0,2 \mathrm{~N}$ dihasilkan gaya otot bisep sebesar 0,4 $\mathrm{N}$ dan gaya pada siku sebesar 0,3. Pada beban paling berat yaitu $1 \mathrm{~N}$ memerlukan gaya otot 1,9 $\mathrm{N}$ dan gaya siku 1,5 N. Lengan bagian siku berada dalam kondisi statis, sehingga resultan momen pada siku harus bernilai nol. Momen yang timbul akibat gaya eksternal terkompensasi oleh momen internalnya.

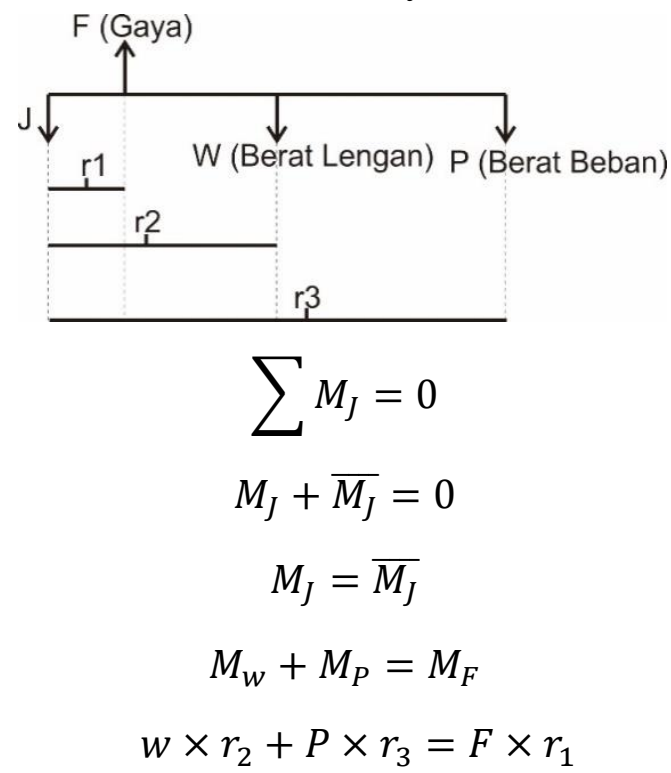

Keterangan

$\begin{array}{lll}M_{J} & =\text { momen siku } & (\mathrm{Nm}) \\ \overline{M_{J}} & =\text { momen internal siku } & (\mathrm{Nm}) \\ M_{w}=\text { momen pada berat lengan } & (\mathrm{Nm}) \\ M_{P}=\text { momen pada berat beban } & (\mathrm{Nm}) \\ M_{F}=\text { momen pada gaya otot } & (\mathrm{Nm}) \\ w & =\text { berat lengan } & (\mathrm{N}) \\ P & =\text { berat beban } & (\mathrm{N}) \\ F & =\text { gaya otot biep } & (\mathrm{N}) \\ r_{1} & =\text { jarak F terhadap siku } & (\mathrm{m}) \\ r_{2} & =\text { jarak w terhadap siku } & (\mathrm{m}) \\ r_{3} & =\text { jarak P terhadap siku } & (\mathrm{m})\end{array}$


Persamaan (1) di atas menunjukkan hubungan berat beban dengan gaya otot bisep. Semakin besar nilai berat beban maka semakin besar pula nilai gaya otot bisepnya. Pada grafik juga nampak perbedaan kenaikan gaya otot yang lebih besar dibandingkan kenaikan gaya siku saat kerangka lengan diberi penambahan beban. Hal ini disebabkan saat diberi beban gaya otot yang lebih menerima dampak secara langsung dibandingkan gaya siku. Hal ini menyebabkan peningkatan gaya otot labih cepat dibandingkan gaya siku.

Muslimah dkk menjelaskan bahwa menurut NIOSH (National Institue of Occupational Safety and Health) batasan gaya angkat normal meliputi batasan dari aspek psikofisik, biomekanik dan fisiologi ${ }^{[5]}$. Waters et al. juga menjabarkan bahwa batasan psiko-fisik adalah beban yangdiangkat harus dapat diterima oleh $75 \%$ wanita dan $90 \%$ pria $^{[6]}$. Batasan biomekanik membatasi besarnya gaya tekansebesar 3,4 KN (770 lbs) pada tulang punggung (L5/S1), dan batasan fisiologi membatasi pengeluaran energimaksimum sebesar 2,2 - 4,7 $\mathrm{Kkal} / \mathrm{min}$. Seseorang yang bekerja di dunia industri khususnya bagian angkat barang dengan menggunaakan lengan harus memperhatikan berat beban maksimal agar tidak terjadi resiko cedira pada lengannya.

\section{KESIMPULAN}

Berdasarkan hasil penelitian yang telah dilakukan tentang pengaruh berat beban terhadap gaya otot bisep maka dapat disimpulkan bahwa semakin besar berat beban yang diberikan pada lengan maka semakin besar pula gaya otot bisep dibutuhkan. Dari hasil dan pembahasan juga diketahui bahwa peningkatan gaya otot bisep terhadap penambahan berat beban lebih besar dibandingkan peningkatan gaya siku terhadap penambahan berat beban.

Adapun penelitian ini memiliki beberapa kelemahan, sehingga perlu adanya solusi untuk penelitian selanjutnya. Peneliti memberikan saran untuk penelitian selanjutnya yaitu: model kerangka lengan dibuat sedemikian rupa sehingga ukurannya lebih mendekati ukuran asli pada lengan manusia normal, dan neraca yang digunakan lebih baik menggunakan neraca yang memiliki kekuatan lebih besar dan memiliki tingkat ketelitian yang lebih besar seperti neraca digital.

\section{DAFTAR PUSTAKA}

1. BSNP. 2008. Pedoman Penyusunan Kurikulum Tingkat Satuan Pendidikan Jenjang Sekolah Dasar. Jakarta: BSNP.

2. Chaffin, D. B., \& Page, G. B. 1994. Postural effects on biomechanical and psychophysical weight-lifting limits. Journal Ergonomics, 37(4), 663-676.

3. P, A.P., Rahayu, S., Subiyono, H.S. 2014. Pengaruh Senam Sang Surya Terhadap Kekuatan Otot Tungkai Dan Kelentukan Togok Lansia Di Padepokan Tapak Suci Banjarnegara Tahun 2013. Journal of Sport Sciences and Fitness, 3(1), 8-12.

4. Granata, K. P., Marras, W. S., \& Davis, K. G. 1997. Biomechanical assessment of lifting dynamics, muscle activity and spinal loads while using three different styles of lifting belt. Clinical Biomechanics, 12(2), 107-115.

5. Muslimah, E., Anis, M., \& Mulyaningrum, R. A. 2009. Analisis Aktifitas Angkat Beban Ditinjau Dari Aspek Biomekanika Dan Fisiologi, Simposium Nasional RAPI VIII.

6. Waters, T. R., Putz-Anderson, V., Garg, A., \& Fine, L. J. 1993. Revised NIOSH equation for the design and evaluation of manual lifting tasks. Journal Ergonomics, 36(7), 749-776. 